\title{
Editorial \\ Leveraging the Power of Social Work through Interprofessional Education
}

\author{
Maureen Rubin \\ Lise de Saxe Zerden \\ Lisa McGuire
}

Interprofessional education (IPE) "occurs when students from two or more professions learn about, from and with each other to enable effective collaboration and improve health outcomes" (World Health Organization [WHO], 2010). With a commitment to foster collaborative practice, social work faculty have provided leadership in incorporating IPE in social work and other discipline's curricula and training for more than a decade (Konrad et al., 2017; Nimmagadda \& Murphy, 2014; Jones \& Phillips, 2016). Yet, now more than ever, as the country and world grapple with responding to the COVID-19 pandemic and the resultant deleterious impacts on society, effective collaboration has never been more critical. Likewise, the Black Lives Matter (BLM) movement has impacted the nation as the country reckons with racial and social disparities across every sector of society. The impetus for this special issue pre-dated the COVID-19 and BLM momentum; however, the 19 papers included in this special issue highlight the interconnected nature of social conditions across systems that necessitate interprofessional, coordinated responses. This special issue reinforces the importance of collaboration, teamwork, inclusivity, and diversity. The power of social work, in partnership with other professions and/or disciplines, in communities locally and globally is essential to effectively meeting some of society's greatest challenges.

\section{Context of IPE in Social Work}

Across many fields of practice, social workers have been involved in collaborative practice, likely since the founding of the profession. Recent findings from the National Academies of Science, Engineering, and Medicine (2019) Consensus Study focuses on the need to integrate social care in health care delivery and serves as an important milestone for the profession to be recognized as an integral part of improving the nation's health. Although IPE has been around for several decades, in the late 1990s and early 2000s, health systems began to identify the vital need for improved outcomes across several complex health challenges (WHO, 2010). The social work profession saw a renewal in how their perspective was valued to address complex and intersecting social conditions. As social determinants of health came to be more understood as driving factors in inequitable outcomes, social work has seen growth in how others recognize the value of the social work profession. It has become increasingly apparent that systemic change is needed and requires social work's expertise to promote and renew health and wellness in the lives of individuals, families, groups, and communities as well as to impact policy development.

The emphasis on the social determinants of health has led to a renewed emphasis on IPE in social work programs and the education of future practitioners. In 2015, IPE was formally introduced to the profession in the Educational Policy and Accreditation Standards (EPAS). Inclusion in EPAS signaled that IPE is an essential component of required social work competencies to prepare students for

\footnotetext{
Maureen Rubin, MA, MSW, Ph.D., Director, Calming Chaos Co., Burr Ridge, IL. Lisa de Saxe Zerden, MSW, PhD, Senior Associate Dean for MSW Education John A. Tate Early Career Scholar for Children in Need UNC Chapel Hill School of Social Work Chapel Hill, NC. Lisa E. McGuire, MSW, PhD, Social Work Department Head, James Madison University, Harrisonburg, VA. 
professional practice. In 2016, the Council on Social Work Education (CSWE) became a member of the Interprofessional Education Collaborative (IPEC), which included the profession's voice on par with other health professions to promote, encourage, and support collaborative practice. Recently, social work has joined with 23 other professions to communicate and collaborate among their accrediting bodies to develop quality IPE (Health Professions Accrediting Collaborative, 2019).

Social work involvement in IPE and collaborative practice initiatives has been evident over the years as early adopters participated in and "voiced" the role of the profession in formal professional networking opportunities such as the Nexus Summit (held annually in Minnesota and co-hosted by the National Center for Interprofessional Practice and Education), the American Interprofessional Health Collaborative (AIHC), and the National Collaborative on Improving Clinical Learning Environments (NCICLE), or the All Together Better Health (ATBH), an international conference (held biennial) organized by the Interprofessional.Global. In 2018, the Chair of the CSWE Council on Conferences and Faculty Development, along with IPE leaders across the nation, worked to develop a one-day Summit on IPE in conjunction with the Annual Program Meeting, organized by CSWE. Thought leaders were invited to share their work and discuss ways to advance IPE within social work education and bolster IPE with other professions to foster collaborative practice. One of the outcomes of this summit was a call for a special issue dedicated to social work's role within IPE. Thus, Advances in Social Work agreed to publish a special issue on social work and IPE as a way to collate empirical work, advance the professions' leadership in the field, and explore applications of IPE and collaborative practice across the micro-macro continuum. This special issue highlights how the integration of social work with other disciplines has advanced innovative programs, resulted in novel teaching activities and learning opportunities, and promoted shifting perspectives to embrace client and community well-being. Furthermore, as is described within the included articles, IPE is presented as a way for learners and practitioners to gain insight into their own professional identity and to identify ways to partner in a mutually respectful professional engagement.

Interestingly, in alignment with EPAS 2015, we noticed that the terms "interprofessional" and "interdisciplinary" were used interchangeably as we have seen in some of the included articles. Smith and Clouder (2010) provide clarification on the differences and similarities of the terms "interdisciplinary" and "interprofessional" in their analysis of various definitions used by scholars from different vantage points over the years. Disciplines can be understood as a branch of learning or field of study that typically includes theoretical and methodological contributions whereas "professions" are associated with "ideology....occupation or career, vocation, or calling, which involves advanced or specialized knowledge" (p. 2). Professions have values, beliefs, and ethics and fall within official regulatory bodies, and often involve licensing of some kind to serve the public (Smith \& Clouder, 2010). Webster's dictionary defines interprofessional as work "occurring between or involving two or more professions or professionals" while interdisciplinary is defined as "involving two or more academic, scientific or artistic disciplines."

In this issue, we conceptualize "interprofessional" as being inclusive of social work, health and allied professions, and "interdisciplinary" encompassing business, art, technology, and others that may fit the definition of a discipline. 


\section{Social Work Everywhere}

The literature and evidence to support IPE in social work is emerging and shows promise as demonstrated by the array of articles within this special issue. Social work programs have been creative in collaborating with units across campus, between and among other campuses, and through community partnerships to infuse IPE in numerous ways to enhance collaborative practice and develop collaborative practitioners. While IPE is most frequently cited within health care or clinical settings (Thistlethwaite et al., 2010; Zwarenstein et al., 2000), as guest editors, we were purposeful to include examples of IPE that partnered with other fields such as nursing, law, oral health, recreational therapy, public health, pharmacy, and others, to highlight the breadth of social work practice across the life course, micro-macro continuum, in the U.S. and internationally. Readers will see applications of IPE concepts developed and applied in various settings that include physical and behavioral health, child welfare, geriatrics, human trafficking, public libraries, and policies. In this regard, social work, along with other professions, contributes in settings everywhere.

Within this issue, we are pleased to highlight the conceptualization, design, and implementation of core social work values across sectors. One of the highlights of this special issue includes the diversity of articles published and their approach to furthering the social work profession's impact through interprofessional efforts across the micro, mezzo, and macro continuum. As guest editors, categorizing the following papers was not an easy feat given the unique features of each article but also their shared similaritiesmainly in promoting how the social work voice enhanced efforts and contributed to solutions. However, in an effort to capture common themes and extend social work's role in IPE and collaborative practice in a systematic manner, we have organized this special issue around four broad domains: (a) IPE and Curricula Exemplars, (b) Simulation and Field Education, (c) Macro Practice and Policy, and (d) Social Work Leadership.

\section{IPE and Curricula Exemplars}

Mapping accreditation standards to curriculum and to the granular level of courses ranging from foundation to advanced levels is a comprehensive task in social work education. The transition to competency-based education in social work in 2008 (CSWE, 2008) provided an impetus to measure knowledge, values, and skills that students need to demonstrate to progress through the program. The 2015 EPAS (CSWE, 2015) has nine competencies and IPE is included in competencies 1, 6, 7, and 8. For example, competency 8 states "... Social workers value the importance of inter-professional teamwork and communication in interventions, recognizing that beneficial outcomes may require interdisciplinary, inter-professional, and inter-organizational collaboration."

One method of providing IPE content in social work education is through a dedicated course. As an exemplar, Mulvaney and colleagues describe a course addressing the needs of older adults focusing on the practice, knowledge, and skills of health professions students across nine disciplines. This article describes a competitive, gamified team-based learning approach and other experiential learning opportunities for students to improve practice skills in geriatric care. Within the special issue, two articles focus on the curricular 
response to the opioid epidemic. Kim, Elze, and Ohtake describe how a case-based discussion enhanced social work students' attitudes and self-efficacy measured by pre-andpost-test ratings. IPE was offered through the Office of Interprofessional Education with support from Schools of Medicine and Biomedical Sciences, Dental Medicine, Nursing, Pharmacy and Pharmaceutical Sciences, Public Health and Health Professions, and Social Work. Stoddard-Dare and colleagues discuss how a large IPE training event for social work, pharmacy, medicine, nursing, occupational therapy, physical therapy, and speechlanguage pathology students facilitated participants' critical thinking about pain management and reversing opioid overdose trends in their state. Given the multifaceted ways people with substance misuse interact with a variety of service systems and health professions, these papers demonstrate how addiction cannot be effectively addressed in silos as well as how IPE engagement is a step towards improved service delivery. These articles may help readers replicate something similar within their social work programs to address the complex challenges of substance misuse.

Several of the papers highlight innovative programming, assessment, and student engagement activities to strengthen IPE and enhance collaboration. For instance, Giesler and colleagues describe how the specialized needs of children and families in rural southeastern Idaho have been interprofessionally addressed by students in an IPE course for more than 30 years. The knowledge, impact, and competency gains of students involved in this course serve as an exemplar, while also providing a focus on the unique needs of rural communities. Levine, Sutherland, and Janzen apply IPE concepts to the child welfare and school systems to work within these large systems to improve services to highly vulnerable children.

\section{Simulation and Field Education}

As field education is the signature pedagogy of social work education, students must learn to apply knowledge gained through their courses to demonstrate their social work values and skills, as well as their cognitive and affective processes in practice (CSWE, 2015). Realistically, not all field placements are able to provide opportunities to facilitate students to master competency in all nine areas; hence, some educators have enhanced students' ability to gain required competencies by using simulation experiences. Field education and simulation are fertile opportunities for innovative IPE learning endeavors with several other professionals. While IPE has been emphasized in federal grants such as the Health Resources Service Administration Behavioral Health Workforce Education and Training grants (BHWET) for MSW students (Fraher et al., 2018; Mancini et al., 2019; Rubin \& Kilgore, 2020; Zerden et al., 2017), several manuscripts in this special issue operationalize what this means for students and field instructors. Padykula, Berrett-Abeb, and Haven conducted a needs assessment to prepare agencies more systematically for integrated, interprofessional education realities to enhance the quality of field education for BHWET trainees. Another paper related to field placement by Clarkson-Hendrix and Warner examined students' satisfaction with integrated behavioral health field placement experiences with other disciplines.

Also, within field education, Kozakiewicz, Pope, and Battjes describe a program from the Michigan State University School of Social Work to train future social workers 
and lawyers from an interprofessional perspective through a variety of community-based advocacy projects that involve law and social work services for children. Preliminary results are promising and demonstrate how this program has achieved intended outcomes across a variety of stakeholders. Likewise, Copenhaver and Crandell-Williams focus on the role of IPE at the Bachelors level, something that is often overlooked within the literature. In this study, undergraduate social work and nursing students participated in clinical supervision groups during their field experiences. Quantitative and qualitative results demonstrated student-participants enhanced their interprofessional knowledge and communication skills. Another example that reinforces the need for communication and collaboration skills can be found in It's Time to Go! Unfolding Interprofessional Simulations to Health Care Communications by Kolomer and Cunningham. In this work, students from three healthcare disciplines participated in simulations with patient actors to increase communication and collaboration skills used in hospital discharge planning and follow-up care in a home setting. Relatedly, Hitchcock and colleagues' paper titled Using a Standardized Patient Model for Interprofessional Team Training in Social Work focused on a single-session training for the development of a treatment plan, using a case study augmented with video technology and the use of standardized patients.

\section{Macro Practice and Policy}

As a profession that has long embraced an ecological perspective and has worked to facilitate change across system levels, it is exciting to see the concepts of interprofessional collaborative practice and IPE applied beyond direct service situations and to include human rights, policy practice, and community development. This special issue highlights several unique and innovative partnerships to address important challenges facing our society. One such example was operationalized by Deluca-Acconi, Velazquez, Rabeno, and Graham who describe a curriculum in partnership with a human rights organization to better prepare the next generation of advocates. They engaged in IPE with BSW students to understand, defend, and advocate for human rights and the pursuit of systemic change. Likewise, in The Creation of a Human Trafficking Course: Interprofessional Collaboration from Development to Delivery, Lucio, Rapp-McCall, and Campion describe how they successfully delivered a course on human trafficking to a non-profit agency in Africa using an asynchronous, online, interprofessional course. The authors describe the life cycle of the project from conceptualization to implementation and conclude by sharing initial impacts of their efforts.

Social work has been integrated into community practice and non-traditional settings, which underscores the social considerations emerging in places that have not always understood what the profession brings to the table. Soska and Navarro's efforts to bridge social work professionals and social work services within public libraries describes how this partnership has been successful in efforts across the country and how to further encourage this type of interprofessional collaboration throughout communities across the country. 


\section{Social Work Leadership}

An exciting group of articles highlight the important leadership roles that social work programs are taking in the area of IPE. Social workers bring a systems perspective and an understanding of group work and policy practice, ideally suited to champion IPE activities across the bureaucracies of higher education. In order to build effective educational experiences that prepare students for modern practice, academic units must overcome barriers to working outside of their academic unit. At times this requires working with a program next door, across campus, or sometimes across institutions.

Articles included within this special edition provide exemplars for how social work knowledge and skills are highly valued in the creation and expansion of IPE endeavors. The voice and leadership of social work is exemplified in the Jones et al. article that highlights a team-based approach to a longitudinal course in partnership with a medical school. Social work's leadership resulted in learners' enhanced sense of identity and purpose as they continued through their health professions' training. Rishel, Guthrie, and Hartnett in Who Am I and What Do I Do? Developing a Social Work Identity through Interprofessional Education and Practice, examine the importance of a cohesive professional identity for social work students. This paper explains how a training program to prepare students for collaborative practice in integrated behavioral health settings was developed and implemented, also connecting to the BHWET IPE efforts previously mentioned. The importance of social work leadership is further demonstrated by Adamson, Ashcroft, Langlois, and Lising as they share lessons in the development of a universitywide IPE partnership in Canada. These authors discuss how social work leadership facilitated meaningful IPE learning experiences and consider the implementation factors that include scheduling, administrative complexities, and participation through faculty leadership.

Amato et al.'s Jumpstarting Cross-disciplinary Collaboration in Undergraduate Social Work Education focuses on the interprofessional training of undergraduate teacher education students along with social work and pre-occupational therapy students. These authors describe a 2-year long project in a K-12 setting and highlight the importance of IPE being expanded into non-healthcare settings. In the final article of this special edition, McCave, Mutrie, Doyle, Jacobsen, and Kelly demonstrate how social work can transform IPE partnerships. They incorporate a change leadership model to analyze the integration of the MSW program in the current IPE curriculum. Their findings highlight the importance of creativity, adaptability, advocacy, and relationship-building as key skills for social workers to promote and implement IPE.

In summary, there are a few key themes that stand out in looking at IPE in its entirety. The first key theme is the breadth of social work educators, across the U.S. and Canada, who are using IPE in innovative ways. This includes innovations across program levels (both BSW and MSW) as well as across service delivery systems and at the micro, mezzo, and macro levels. Second, it is clear that social work educators are striving to fulfill the professional mission of social work by promoting collaborative practice to improve client well-being while continuing to advocate for social and economic justice for several vulnerable populations including foster children, people with substance misuse those who 
are homeless and older adults. The social work voice seems well-respected when raising issues around health disparities, unequal access to services, and ethical practice concerns which seemingly could have a powerful impact on both IPE, collaborative practice, and the overall quality of healthcare delivery. Finally, social work educators are contributing their considerable professional knowledge and skills to improve IPE and practice by bringing expertise in areas such as an ecological perspective, group/team building, cultural humility, engagement skills, and a deep understanding of the social determinants of health. It is no surprise that social workers are becoming leaders in the development and implementation of interprofessional education.

\section{Looking Forward}

It has been a joy to read and work with so many social work educators who are actively engaged in IPE. Given the breadth of articles presented in this special issue, social work professional involvement clearly has potential to address these complex social challenges across systems. An overview of the articles in this issue also raises some important questions about the future of IPE in social work and health and social services in general. One way forward is to think of IPE engagement as a continuum and an ever-present responsibility to fulfill our professional mission. Many of the examples included initiatives that should be engrained and sustained rather than being time limited. IPE warrants continual engagement and assessment to evaluate how it impacts practice across multiple service delivery systems and the desired outcomes it is intended to achieve. The articles in this special issue provide a glimpse into the kinds of practice that have the potential to make great impact and hopefully inspire additional innovations given the continuing challenges before us. Future research is needed to evaluate the long-term impact of these educational efforts to determine how they translate to lasting practice change and system transformation. While IPE is important at the individual student learner and curriculum levels, more information is needed about how this translates to population health outcomes.

As is evident from the articles included in this special issue, IPE in social work has grown exponentially over the last decade. Developmentally, the time is right for the profession to examine ways to sustain innovative programming and ensure IPE is threaded through mainstream curriculum in undergraduate and graduate level social work programs. This requires further work on the upcoming 2022 EPAS revisions in how IPE is conceptualized and integrated within the competencies. There is some concern that IPE, as it currently exists within EPAS, may be interpreted by programs as an additional bonus rather than as a clear expectation for all student learners enrolled in accredited programs. Our hope is that this special issue may spur additional interprofessional learning experiences to ensure more comprehensive infusion through social work curricula and assessment of such competencies. Working with administrators, faculty, and others across campus to determine what competencies and accreditation needs can be met across programs through IPE efforts may be one way to initiate and sustain change.

Additional challenges have come with the growth of online programs across the nation, and the rapid transition to remote instruction given the COVID-19 pandemic. It will be interesting to learn how best to creatively engage in IPE and to prepare the future workforce for collaborative practice using virtual technology. It is possible that programs are 
collaborating with field agencies to infuse IPE or could be using online learning management systems. However, building an evidence-base on conceptualization, implementation, and impact will continue to benefit the profession, and ultimately, those who receive social work services.

While simulation and/or standardized patients are used in some programs, as evidenced in some papers in this issue, there remains limited research from social work to support this work. It may be that not all universities have the resources needed for a simulation lab or have access to existing simulation equipment. Therefore, finding ways to partner with units on campus who have these resources may be a place to start. Further, there is increased availability of virtual simulation programs and trainings which may be available online that do not require physical space or equipment. We look forward to seeing an expansion of the literature on simulations and best practices engaging standardized patients in IPE initiatives.

While discussing these innovations, it is important to note that there are many administrative barriers that make IPE somewhat complicated or difficult to implement (Breitbach et al., 2013; Hammick et al., 2007). Often, administrative processes can stifle IPE collaboration, including divergent academic calendars, field vs. classroom schedules, diverse registration processes, to name a few common challenges. An additional layer involves the practicality of financing IPE. As workload credits and expectations are unique at each institution, it remains tricky to pay for IPE development, teaching, and related activities. These financial constraints to IPE need further attention. While there is no easy answer to these barriers, our vision for programs is to start small and include additional professions and disciplines as the activity continues. IPE activities should not be a volunteer labor of love and it will be up to social work educators and administration to recognize the value and investment that is required for quality IPE activities. This is certainly an area in need of further research and development.

As the COVID-19 pandemic and response continues to impact how social work education will be offered in the immediate and not-so-distant future, educators will be challenged to consider how IPE can be integrated into what is already an unprecedented learning environment. Despite the challenge, the articles in this issue inspire hope that it is possible - and vital. Undoubtedly, the lessons from within this special issue speak to the central themes of collaboration, teamwork, social justice, and the power of social work to provide more holistic services. As IPE champions and guest editors for this special issue, we recognize that the synergy between the ethos of social work and key features of IPE are strongly aligned. Social work educators and practitioners need to own this expertise. We are grateful to Advances in Social Work and all contributing authors for highlighting what we do as a profession, how we contribute across a variety of sectors, and our impact on general and specialized population groups. Without shining a light on these efforts, others may not know the innovation, creativity, and leadership that the social work profession brings to IPE.

\section{References}

Breitbach, A. P., Sargeant, D. M., Gettemeier, P. R., Ruebling, I., Carlson, J., Eliot, K., Kienstra, K., \& Gockel-Blessing, E. A. (2013). From buy-in to integration: Melding 
an interprofessional initiative into academic programs in the health professions. Journal of Allied Health, 42(3), 67E-73E.

Council on Social Work Education [CSWE]. (2008). Educational Policy and Accreditation Standards for Baccalaureate and Master's Social Work Programs. https://cswe.org/getattachment/Accreditation/Standards-and-Policies/2008EPAS/2008EDUCATIONALPOLICYANDACCREDITATIONSTANDARDS(EPA S)-08-24-2012.pdf.aspx

CSWE. (2015). Educational Policy and Accreditation Standards for Baccalaureate and Master's Social Work Programs. https://www.cswe.org/getattachment/Accreditation/Accreditation-Process/2015EPAS/2015EPAS_Web_FINAL.pdf.aspx

Fraher, E. P., Richman, E. L., Zerden, L. D., \& Lombardi, B. (2018). Social work student and practitioner roles in integrated care settings. American Journal of Preventive Medicine, 54(6), S281-S289. https://doi.org/10.1016/j.amepre.2018.01.046

Hammick, M., Freeth, D., Koppel, I., Reeves, S., \& Barr, H. (2007). A best evidence systematic review of interprofessional education: BEME Guide no. 9. Medical Teacher, 29(8), 735-751. https://doi.org/10.1080/01421590701682576

Health Professions Accreditors Collaborative. (2019). Guidance on developing quality interprofessional education for the health professions. Health Professions Accreditors Collaborative. https://healthprofessionsaccreditors.org/wpcontent/uploads/2019/02/HPACGuidance02-01-19.pdf

Jones, B., \& Phillips, F. (2016). Social work and interprofessional education in health care: A call for continued leadership. Journal of Social Work Education, 52, 18-29. https://doi.org/10.1080/10437797.2016.1112629

Konrad, S., Cavanaugh, J., Rodriguez, K., Hall, K., \& Pardue, K. (2017). A five-session interprofessional team immersion program for health professions students. Journal of Interprofessional Education \& Practice, 6, 49-54. https://doi.org/10.1016/j.xjep.2016.12.007

Mancini, M. A., Maynard, B., \& Cooper-Sadlo, S. (2019). Implementation of an integrated behavioral health specialization serving children and youth: Processes and outcomes. Journal of Social Work Education, 1-16. https://doi.org/10.1080/10437797.2019.1661905

National Academics of Sciences, Engineering, and Medicine. (2019). Integrating social care into the delivery of health care: Moving upstream to improve the nation's health. The National Academies Press. https://doi.org/10.17226/25467

Nimmagadda, J., \& Murphy, J. I. (2014). Using simulations to enhance interprofessional competencies for social work and nursing students. Social Work Education, 33, 539548. https://doi.org/10.1080/02615479.2013.877128 
Rubin, M., \& Kilgore, R. (2020). Integrated care workforce development: Universitycommunity collaboration, Social Work Education, 39(4), 534-551, https://doi.org/10.1080/02615479.2019.1661987

Rubin, M., Konrad, S., Nimmagadda, J., Scheyett, A., \& Dunn, D. (2018). Social work and interprofessional education: Integration, intersectionality, and institutional leadership, Social Work Education, 37(1), 17-33, https://doi.org/10.1080/02615479.2017.1363174

Smith, S., \& Clouder, L. (2010). Interprofessional and Interdisciplinary Learning: An Exploration of Similarities and Differences. In A. Bromage, L. Clouder, J. Thistlethwaite, \& F. Gordon (Eds.), Interprofessional E-Learning and Collaborative Work: Practices and Technologies (pp. 1-13). IGI Global. https://doi.org/10.4018/978-1-61520-889-0.ch001

Thistlethwaite, J., Moran, M., \& World Health Organization [WHO] Study Group on Interprofessional Education and Collaborative Practice. (2010). Learning outcomes for interprofessional education (IPE): Literature review and synthesis. Journal of Interprofessional Care, 24(5), 503-513. https://doi.org/10.3109/13561820.2010.483366

WHO. (2010). Framework for action on interprofessional education and collaborative practice. https://apps.who.int/iris/handle/10665/70185

Zerden, L. D. S., Jones, A., Brigham, R., Kanfer, M., \& Zomorodi, M. (2017). Infusing integrated behavioral health in an MSW program: Curricula, field, and interprofessional educational activities. Journal of Social Work Education, 53(sup1), S59-S71. https://doi.org/10.1080/10437797.2017.1288595

Zwarenstein, M., Reeves, S., Barr, H., Hammick, M., Koppel, I., \& Atkins, J. (2000). Interprofessional education: Effects on professional practice and health care outcomes. Cochrane Database of Systematic Reviews, (3). https://doi.org/10.1002/14651858.cd002213

Author note: Address correspondence to Maureen Rubin, Calming Chaos Co., Burr Ridge, IL. Email: rubinm10@gmail.com

Acknowledgement: We are grateful for the tireless support and guidance of Assistant Editor, Valerie Decker, through this process. 